\title{
Urban Green Space Growth Impact on Surface Temperature Distribution
}

\section{Siti Nor Afzan Buyadi, Wan Mohd Naim Wan Mohd, Alamah Misni}

Faculty of Architecture, Planning and Surveying, Universiti Teknologi MARA, 40450 Shah Alam, Selangor

n_afdzsan@yahoo.com

\begin{abstract}
Trees and vegetation play a vital role to mitigate urban heat island (UHI) effects. Land use, vegetation growth detection and land surface temperature (LST) maps of two different dates are generated from Landsat 5 TM (1991 and 2009) in the city of Shah Alam. The conversion of natural green areas into residential and commercial development significantly increases the LST. The result reveals that mature trees in urban green space help to mitigate the effects of UHI as well as to sustain the urban development.
\end{abstract}

Keywords: trees; land surface temperature (LST); urban; development

eISSN 2514-751X @ 2018. The Authors. Published for AMER ABRA cE-Bs by e-International Publishing House, Ltd., UK. This is an open-access article under the CC BY-NC-ND license (http://creativecommons.org/licenses/bync-nd/4.0/). Peer-review under responsibility of AMER (Association of Malaysian Environment-Behaviour Researchers), ABRA (Association of Behavioural Researchers on Asians) and cE-Bs (Centre for EnvironmentBehaviour Studies), Faculty of Architecture, Planning \& Surveying, Universiti Teknologi MARA, Malaysia DOI: https://doi.org/10.21834/aje-bs.v3i10.327 


\subsection{Introduction}

The urban heat island $(\mathrm{UHI})$ phenomenon has been found in cities throughout the world. It is defined when the air and surface temperatures are hotter than their rural surroundings (Shahmohamadi, Maulud, Tawil, \& Abdullah, 2011). Due to urbanization demand, the rapid growth of urbanization caused reduction of vegetated areas and increased the built-up surfaces. One of the possible causes of $\mathrm{UHI}$ is a drastic reduction of the greener areas to built-up surfaces. The natural land cover was converted by built surfaces that trap incoming solar radiation during the day and then re-radiate it at night (Solecki, Rosenzweig, Pope, Chopping, \& Goldberg, 2004). Several studies have been carried out in investigating the UHI impacts (Choi, Lee, \& Byun, 2012; Mallick \& Rahman, 2012; Yan, Wang, Hao, \& Dong, 2012). Thus, the seriousness of UHI phenomena cannot be denied and the mitigation strategy should be applied to combat the UHI effects at the macro and micro level.

\subsection{Literature Review}

The impact of the heat island suffered so many people in many ways. The investigation of UHI impacts such as in energy consumption, management of storm water run-off, environmental disturbance, community health, and altering climatic conditions. The UHI project is to produce historic air temperature maps based upon satellite and derived land surface temperature data for multiple years as well as the land use change monitoring. Based on the previous research, the UHI mitigations are discovered and have been applied in subtropic countries (example China and Hong Kong). The mitigation strategies are green/cool roof, use of lighter-colour and reflective surfaces for building. A more practical method of mitigating the $\mathrm{UHI}$ is strategic planting of vegetation in urban areas and designing green technology approach (Ng, Chen, Wang, \& Yuan, 2012; Saffuan, Ariffin, \& Amin, 2013).

The Landsat 5 TM and 7 ETM+ are widely used to derive the land use changes monitoring and land surface temperature retrieval. Additionally, the thermal infrared band of the Landsat imagery is capable of deriving the surface temperature. Previous studies have been developed LST using Landsat 5TM or 7ETM+ to estimate radiation budgets in heat balance studies and as a control for climate models (Buyadi, Mohd, \& Misni, 2013). The remotely sensed image such as Landsat image and GIS technique are used to generate land use map, to monitor the land use changes and as well as their surface temperature map (Mohd, Hashim, \& Noor, 2004; Takeuchi, Hashim, \& Thet, 2010).

It is clearly demonstrated that the implications of rapid urban growth are decreased vegetated areas, increased the surface temperature and modified the urban microclimate. Maturity of the trees and vegetation can be considered as a vital parameter to measure the temperature in urban area through its shadow and transpiration. GIS and ERDAS software, and statistical method are acceptable as technical methodology in analyzing environmental behaviour especially in combating UHI. This study will investigate the land use changes using remote sensing Landsat image and identified the green spaces growth impact on the urban microclimate. 


\subsection{Methodology}

\subsection{Study Area}

The study area consists of part of the Shah Alam City. The area is selected due to rapid urban development activities over the last 30 years. The climate of the cities is categorized as a hot and humid tropical climate. Temperatures tend to remain constant with maximum values of between 31 and $33^{\circ} \mathrm{C}$, while the minimum between 22 and $23.5^{\circ} \mathrm{C}$. Relative humidity is around $72-78 \%$. The geographical location of the study area is shown in Figure 1. The study area is located at $3^{\circ} \mathrm{N}$ Latitude and $101^{\circ} \mathrm{E}$ Longitude in average elevation of $10 \mathrm{~m}$. The meteorological data were obtained from local weather station of Subang, Shah Alam was provided by Malaysia Meteorological Department (MMD), coincide with the time and date of the Landsat TM satellite pass.

\subsection{Generation of land use/land cover maps}

Satellite images are used to generate the land use/land cover maps of two different dates. The detail of satellite image data (Landsat 5 TM) used in this study dated on 21st February 21, 1991 and January 21, 2009 is acquired from the Malaysian Remote Sensing Agency (ACRS). The eighteen year period is selected to ensure the vegetation growth within this study area is matured. The process of generating land use maps is done using the ERDAS Imagine digital image processing software. The unsupervised classification method is used to generate land use/land cover maps. The process based on first-order polynomials and root means square errors (RMSE) obtained less than half of pixel values. The percentages of land use/land cover changes are later calculated. These values of land use/land cover can use to estimate the land use/land cover types individually.

\subsection{Land surface temperature (LST) retrieval}

The thermal infrared band (Landsat 5 TM Band 6) records the radiation in the spectral range between 10.4 and $12.5 \mu \mathrm{m}$ from the surface of the earth. Land surface temperature ia used to provide primary information on the surface physical properties and climate. The monowindow algorithm method is adopted in this study to generate the LST (Sobrino, JiménezMuñoz, Paolini, \& Jime, 2004). The mono-window algorithm requires three parameters; emissivity, transmittance, and effective mean atmospheric temperature. The atmospheric water vapour content and the near surface air temperature are used to calculate the air transmittance and effective mean atmospheric temperature (Liu and Zhang, 2011). The third parameter is emissivity, which is calculated from the normalized difference vegetation index (NDVI). The mono-window algorithm is given as:-

$$
T_{s} \quad\{a(1-C-D)+[b(1-C-D)+C+D] T-D T a\} / C
$$

where:- Ts is LST in Kelvin; $a=-67.355351 ; b=0.458606 ;\left(C=\varepsilon_{i} \times T_{a}\right.$; where $\varepsilon_{i}=$ =emissivity can be computed from NDVI $) ; D=\left(1-T_{a}\right)\left[1+\left(1-\varepsilon_{i}\right) x T_{a}\right] ; T_{i}$ is the brightness temperature $(K)$ and $T_{a}$ is the effective mean atmospheric temperature. 


\subsection{Generation of Normalized Difference Vegetation Index (NDVI) Maps}

GIS spatial analysis and zonal statistical analysis technique are used to visualize the vegetation fragmentation and the surface temperature distribution. Equation 2 is used to calculate the NDVI of the study area. The proposed emissivity values from the different NDVI range; NDVI $<0.2$ (bare soil), $0.2<\mathrm{NDV} \mid<0.5$ (mixture of bare soil, vegetation and hard surfaces) and NDVI> 0.5 (fully vegetated) are $0.99,0.98$ and 0.98 respectively.

$N D V I=(N I R-R) /(N I R+R)$

where

NIR - the pixel digital number (DN) of TM Band 4

$\mathrm{R}$ - DN of TM Band 3

\subsection{Relationship between NDVI and LST}

To obtain the relationship between NDVI and LST, 25 sample points are measured within the detailed study area. Regression analysis is carried out to determine the correlation between these two parameters. The regression equation models are retrieved by fitting the trend line using Microsoft Excel.

\subsection{Results and Discussions}

\subsection{Land use/ Land cover Changes}

The land cover changes for the two dates of part of the Shah Alam City are significantly detected and presented in the land cover maps in Figure 2. The total acreage of the study area is $16,904.547$ hectares. The detail acreage of the individual land cover of the study area is listed in Table 1. Over the period of 18 years, there is a significant decrease in the high dense trees (forest and agricultural land) land cover category. The total area in the mixed vegetation category (crops, parks and bushes) and built-up areas (commercial, residential and administrative building) increased by $11.24 \%$ and $13.63 \%$ respectively. The cleared land decreased due to its conversion to built-up areas. More trees are being planted to replace the lost of natural greenery within the study area.

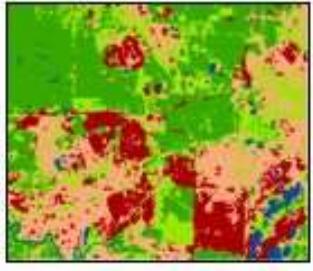

(a)

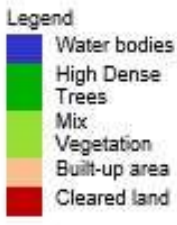

Figure 2: (a) Land use/ Land cover maps of 1991; (b) Land use/ Land cover maps of 2009

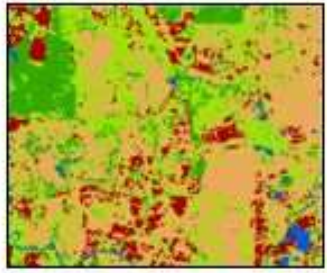

(b) 
Table 1: Land use/land cover coverage

\begin{tabular}{|l|l|l|l|l|l|}
\hline \multirow{2}{*}{$\begin{array}{l}\text { Land Use/Land Cover } \\
\text { Class }\end{array}$} & \multicolumn{4}{|l|}{ Area in Hectare } & $\begin{array}{l}\text { Changes } \\
(\%)\end{array}$ \\
\cline { 2 - 6 } & 1991 & $\begin{array}{l}\text { Percentage } \\
(\%)\end{array}$ & 2009 & $\begin{array}{l}\text { Percentage } \\
(\%)\end{array}$ & \\
\hline (1) Water bodies & 464.554 & 2.75 & 317.827 & 1.88 & -0.87 \\
\hline (2) High Dense Trees & 5726.516 & 34.09 & 2807.432 & 16.61 & -17.48 \\
\hline (3) Mix Vegetation & 3503.806 & 20.73 & 5403.899 & 31.97 & +11.24 \\
\hline (4) Built-up area & 4300.606 & 25.44 & 6608.361 & 39.09 & +13.65 \\
\hline (5) Cleared Land & 2873.065 & 17.00 & 1767.028 & 10.45 & -6.55 \\
\hline Total & $16,904.547$ & 100 & $16,904.547$ & 100 & \\
\hline
\end{tabular}

\subsection{Land surface temperature (LST)}

The LST distributions of 1991 and 2009 are shown in Figure 3. The mean temperature for individual land use/land cover is summarized in Table 2. The lowest and highest radiant temperature for 1991 are $25.8^{\circ} \mathrm{C}$ (in the high density tree area) and $30.8^{\circ} \mathrm{C}$ (in the built-up area). Meanwhile, for 2009 the radiant temperatures range between 24.0 and $38.0^{\circ} \mathrm{C}$. The highest mean temperature is within the built-up area while the lowest is within water bodies. The implication of urban development by replacing natural vegetation to built-up surfaces such as concrete, stone, metal and asphalt clearly can increase the surface radiant temperature. Although there is a significant increase in the built-up areas, the surface temperature is still relatively lower (Figure 3(b)) due to the vegetation growth. On average, over eighteen years of development, regular mature trees, green parks, and other vegetation in urban area potentially can reduce urban temperature and its surrounding.

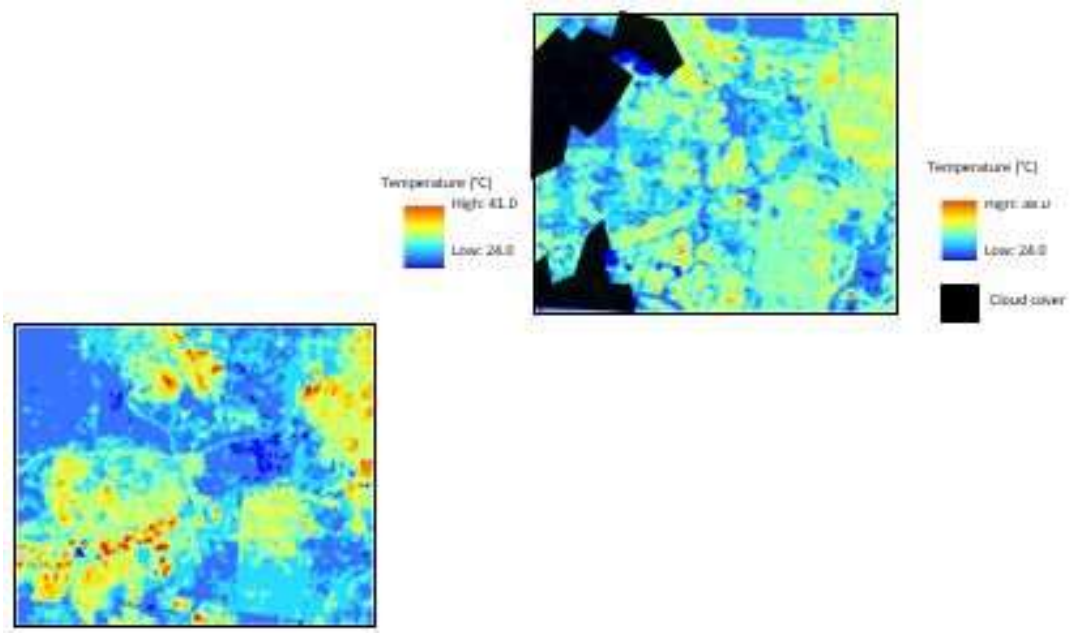

Figure 3: (a) Land surface temperature (1991); (b) Land surface temperature (2009) 


\subsection{Analysis of normalized difference vegetation index (NDVI)}

Figures 4 show the NDVI maps generated from the Landsat 5 TM imagery for the year 1991 and 2009. The increase in the vegetative growth coverage within the study area can clearly be seen due to the maturity of the trees. As the more trees and vegetation within the study area are getting matured, the NDVI value increases and hence lowering the LST.

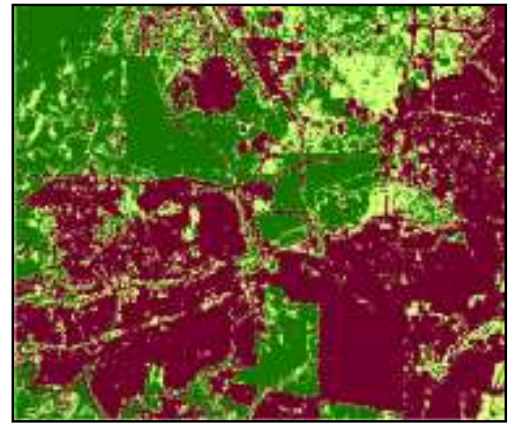

(a)

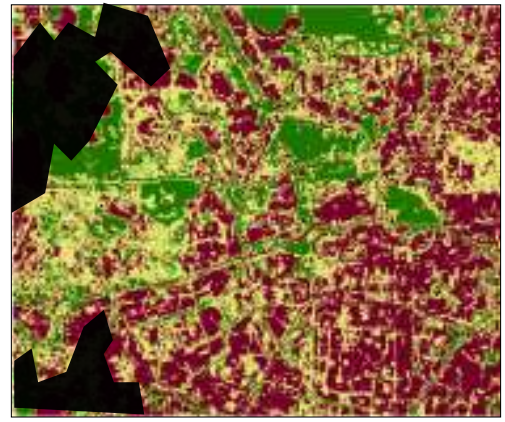

(b)

Legend:

$<0.2$ : Cleared Land and Built-up Area

$0.2 \leq \mathrm{NDVI}<0.5$ : Mix of Built-up/Bare Soil and Vegetation

$\geq 0.5$ : Fully Vegetated

Cloud Cover

Figure 4: (a) Vegetation growth (1991); (b) Vegetation growth (2009)

Aerial photo of 1992 (Figure 5(a)) and digital orthophoto of 2009 (Figure 5(c)) are used to visualize the urban growth of the study area. The lake garden area is surrounded by residential, high rise building, road and commercial areas. Figures $5(b)$ and d) show the NDVI maps of two different dates Figure 5 (b), illustrate that lower NDVI values are clearly evident in water bodies and built-up areas. However, over the period of 18 years, NDVI in these areas significantly increased, although there is no significant change in the coverage of the water bodies and built-up areas. This situation occurred due to the significant vegetation growth within this area. Figure 5(d) shows the NDVI pattern of the year 1991 and 2009, the lower NDVI value is mainly located in the water bodies. Although there is slightly difference between the highest NDVI values, the pixel count for the NDVI higher values in the built-up and vegetated areas significantly increased over the 18 year period in a study area of Shah Alam Lake Garden. Thus, mature vegetation can help to reduce of the hard surface emissivity and lowering the solar exposure of the building envelope as well as cooling down the high temperature in built-up area.

As shown in aerial photo of 1992 (Figure 6(a)), the Kelana Jaya study area is not well developed and exhibit the natural green landscapes. However, due to the rapid urban development, the area has been transformed to the new urban area and the developed area surrounded by mixed development, which is shown in the digital orthophoto of 2009 (Figure 
6(c)). Figures $6(\mathrm{~b})$ and (d) visualized the vegetation decreasing value in the year 1991 and 2009.

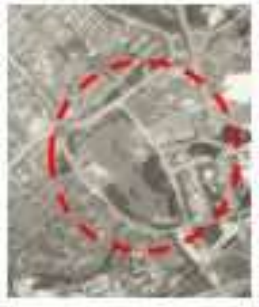

(a) Scanned aerial photo of Shah Alam Lake Garden in 1892

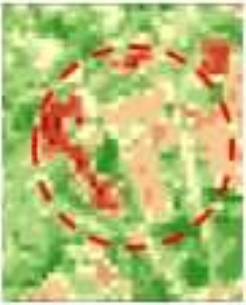

(b) NDV Image 1981 (High:0.457; Low: 0.527 )
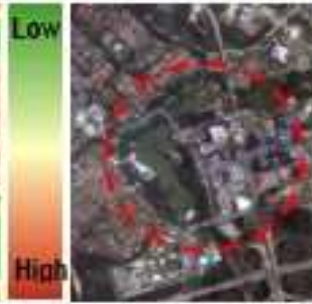

(c) Digital Othophote of Shah Alap Lake Garden in 2008

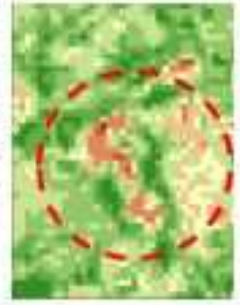

(d) NDY Image 2009

(High:0.464; Low. $0.192)$

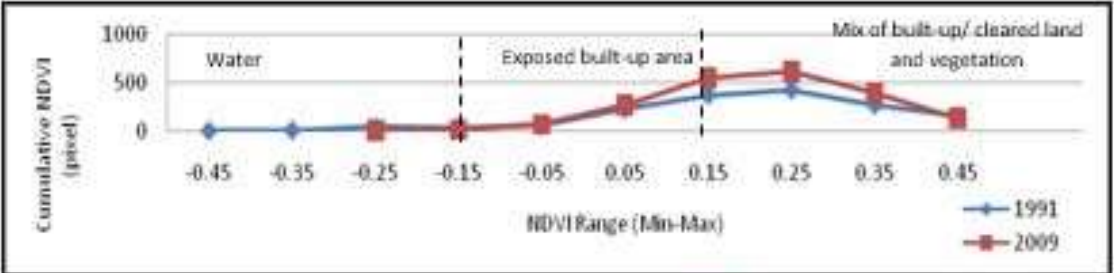

(e) Comparison of NDV pattern in the Shah Blacu Lake Gardens

Figure 5: Aerial images, NDVI maps and NDVI pixel count of the detailed study area

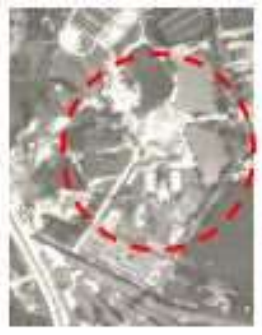

(a) Scanned aerial photo of Bandaran Kelana Park in 1892

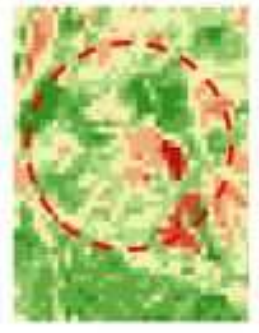

(b) NDV I mage1991 (High:0.523; Low: $0.493)$
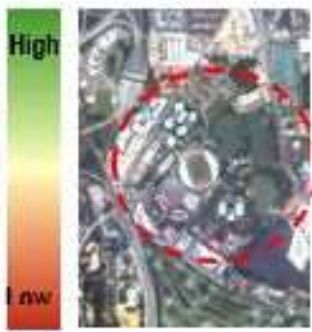

(c) Digital Qrthsphota of Bandacar Kelana Park in 2009

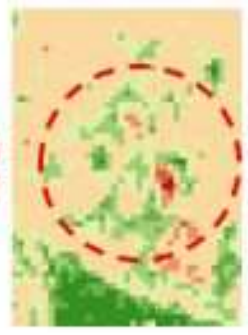

(d) NDV Image 2009 (High:0.504; Low: 0.224)

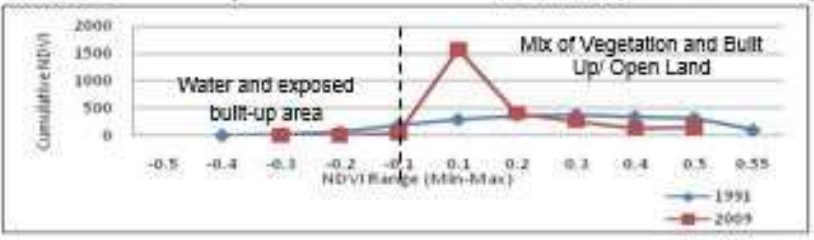

(e) Comparison of NDVl pattern in the Shah Alamo Lake Gardens

Figure 6: Aerial images, NDVI maps and NDVI pixel count of the study area 
Hence, the graph plotted in Figure 6(e) shows the significance of non-vegetation value in 2009 where the ground surfaces are converted to cleared-land and built-up surfaces. Vegetation plays vital roles to alleviate the heat island effect by means of transpiration, shading and heat absorption. High trapped solar radiation in the building may cause high energy usage and disturbing human internal thermal comfort.

\subsection{Correlation between NDVI and LST}

Land surface temperature (LST) is sensitive to vegetation and soil moistures urfaces; hence it was used to detect land use/land cover changes. Various studies have been carried out to investigate LST using the vegetation. Figures 7 show the correlation of LST and NDVI in both clipped study areas in 1991 and 2009.
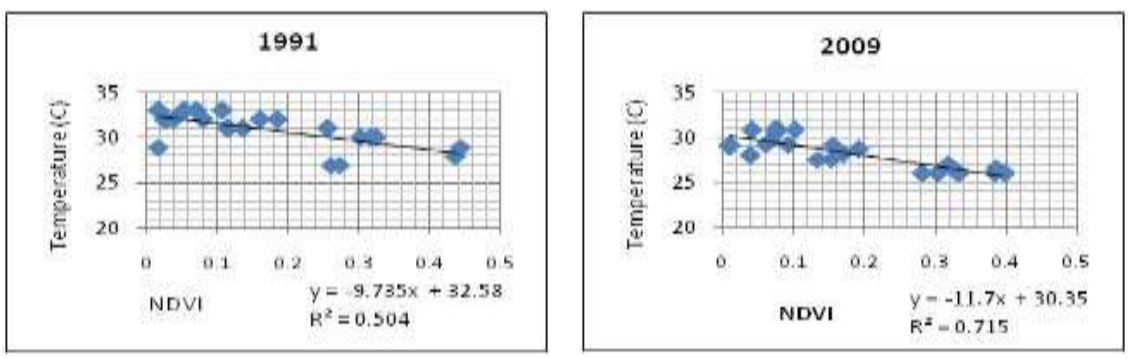

(a) Correlation of LST and NDVI in Shah Alam Lake Garden
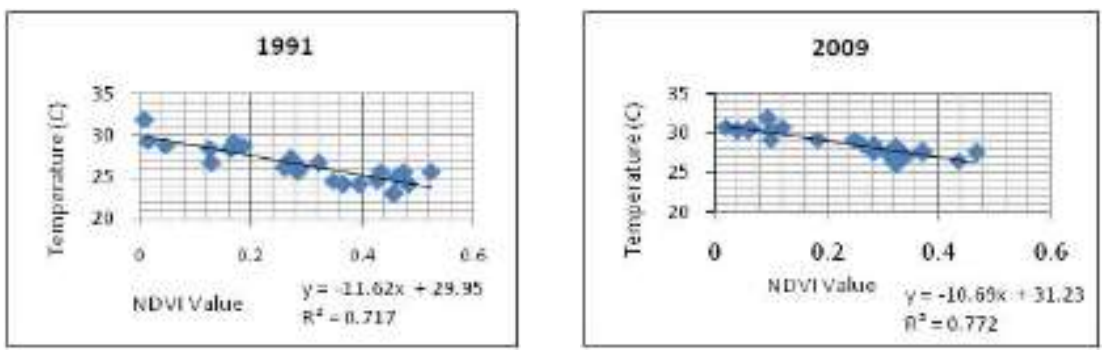

(b) Correlation of LST and NDVI in Bandaran Kelana Park

Figure 7: Relationship of NDVI and LST of the study areas in 1991 and 2009

Strong correlation between surface temperature and NDVI values are found in Shah Alam area are 0.504 and 0.715 in 1991 and 2009. The Kelana Jaya area exhibit strong correlations between surface temperatures and NDVI values are 0.717 and 0.772 in 1991 and 2009 respectively. Precisely, replacing vegetation and greening landscaping in the new urban area can help to reduce the radiant temperature of the built-up area, which significantly important to mitigate the phenomena of $\mathrm{UHI}$. 


\subsection{Conclusion}

Five major classes of land covers; water bodies, high dense trees, vegetations, built-up area, and cleared land have a dramatic changes in land use between 1991 and 2009, where high dense tree land cover areas have relatively decreased about $17.48 \%$. This area is transformed to built-up land cover and cleared land. The results show that LST and thermal signal of built-up and cleared land have distributed to rise average radiant temperature. While the vegetated area and water body experiencing lower temperature. The initial findings have shown that there are significant increases in the built-up areas in the Shah Alam City over a period of 18 years. There is a strong negative correlation between LST and NDVI, which indicates vegetation helps to reduce the LST of an area. Vegetation landscaping in urban areas has high potential to modify hot and humid tropical microclimates in the cities of Malaysia.

\section{References}

Buyadi, S. N. A., Mohd, W. M. N. W., \& Misni, A. (2013). The Impact of Land Use Changes on the Surface Temperature Distribution of Area Surrounding the National Botanic Garden, Shah Alam. AMER International Conference on Quality of Life (p. 10). Pulau Langkawi.

Choi, H., Lee, W., \& Byun, W. (2012). Determining the Effect of Green Spaces on Urban Heat Distribution Using Satellite Imagery. Asian Journal of Atmospheric Environment, 6(June), 127-135.

Elsayed, I. S. M. (2009). A Study on the Urban Heat Island of the City of Kuala Lumpur, Malaysia. IASTED International conference on Environmental Management and Engineering. Alberta, Canada.

Kim, H. M., Kim, B. K., \& You, K. S. (2005). A Statistic Correlation Analysis Algorithm Between Land Surface Temperature and Vegetation Index. International Journal of Information Processing Systems, 1(1), 102-106.

Kumar, K. S., Bhaskar, P. U., \& Padmakumari, K. (2012). Estimation of Land Surface Temperature to Study Urban Heat Island Effect Using Landsat ETM + Image. International Journal of Engineering Science and Technology (IJEST), 4(02), 771-778.

Liu, L., \& Zhang, Y. (2011). Urban Heat Island Analysis Using the Landsat TM Data and ASTER Data: A Case Study in Hong Kong. Remote Sensing, 3(7), 1535-1552.

Mallick, J., Kant, Y., \& Bharath, B. D. (2008). Estimation of Land Surface Temperature over Delhi using Landsat-7 ETM +. J. Ind. Geophys. Union, 12(3), 131-140.

Mallick, J., \& Rahman, A. (2012). Impact of Population Density on the Surface Temperature and Micro-climate of Delhi. Current Science, 102(12).

Mohd, W. M. N. W., Hashim, S., \& Noor, A. M. M. (2004). Integrating Satellite Remote Sensing and GIS for Analysing Urban Heat Island. Built Environment Journal, 1(2), 34-44.

Ng, E., Chen, L., Wang, Y., \& Yuan, C. (2012). A study on the cooling effects of greening in a high-density city : An experience from Hong Kong. Building and Environment, 47, 256-271 
Qin, Z., Karnieli, A., \& Berliner, P. (2001). A Mono-Window Algorithm for Retrieving Land Surface Temperature from Landsat TM Data and Its Application to the Israel-Egypt Border. International Journal of Remote Sensing, 22(18), 3719-3746.

Saffuan, R., Ariffin, J., \& Amin, Z. (2013). Green Technology Design Approach for Liveable Park of Tasik Biru Kundang , Malaysia. Asian Journal of Environmental-Behaviour Studies, 4(11).

Shaharuddin Ahmad, Noorazuan Md.Hashim, Yaakob Mohd Jani, Kadaruddin Aiyub, \& Muhamad Fahmi Mahmod. (2010). The effects of different land uses on the temperature distribution in urban areas. SEAGA 2010, Hanoi. Hanoi.

Shahmohamadi, P., Maulud, K. N. A., Tawil, N. M., \& Abdullah, N. A. G. (2011). The Impact of Anthropogenic Heat on Formation of Urban Heat Island and Energy Consumption Balance. Urban Studies Research, 2011.

Sobrino, J. a., Jiménez-Muñoz, J. C., Paolini, L., \& Jime, J. C. (2004). Land surface temperature retrieval from LANDSAT TM 5. Remote Sensing of Environment, 90(4), 434-440.

Solecki, W. D., Rosenzweig, C., Pope, G., Chopping, M., \& Goldberg, R. (2004). Urban Heat Island and Climate Change : An Assessment of Interacting and Possible Adaptations in the Camden, New Jersey Region. New Jersey.

Takeuchi, W., Hashim, N., \& Thet, K. M. (2010). Application of RS and GIS for Monitoring UHI in KL Metropolitan Area. Map Asia 2010 \& ISG 2010. Kuala Lumpur.

Yan, H., Wang, X., Hao, P., \& Dong, L. (2012). Study on the Microclimatic Characteristics and Human Comfort of Park Plant Communities in Summer. Procedia Environmental Sciences, 13(2011), 755-765. 